\title{
Miswak/Derum Manipulation, a Common Habit in Baluchestan, Iran
}

\author{
Masoomeh Shirzaiy, ${ }^{1, *}$ Zahra Sarani, ${ }^{2}$ and Sudabeh Bagheri ${ }^{3}$ \\ ${ }^{1}$ Oral and Dental Disease Research Center, Dental School, Zahedan University of Medical Sciences, Zahedan, IR Iran \\ ${ }^{2}$ Medical Research Center, Zahedan University of Medical Sciences, Zahedan, IR Iran \\ ${ }^{3}$ Department of Oral Medicine, School of Dentistry, Zahedan University of Medical Sciences, Zahedan, IR Iran \\ "Corresponding author: Masoomeh Shirzaiy, Oral and Dental Disease Research Center, Dental School, Zahedan University of Medical Sciences, Zahedan, IR Iran. Tel: \\ +98-9153498265, Fax: +98-5433414003, E-mail: shirzaiy@gmail.com
}

Received 2015 January 05; Revised 2015 March 16; Accepted 2015 April 29.

Keywords: Dental Caries, Oral Hygiene, Toothbrushing

A teeth-cleaning twig or twig toothbrush- commonly known as a miswak or derum depending on the society and/or culture- is a tool made from a tree that has antimicrobial properties. This traditional tooth brush, or chewing stick, has been used since ancient times. The earliest twig toothbrushes have been found in China dating from 1600 B.C., in an Egyptian tomb from 3000 B.C., and in Babylonia from 3500 B.C. (1).

Today, the miswak is used for oral hygiene in many parts of the world (2), especially in Africa, Asia, south America, Saudi Arabia, and other Islamic countries $(1,3)$. It can prevent gum disease and dental caries $(1,4)$. The miswak has a frayed end that is used to brush the teeth $(1,5)$. The use of a chewing stick leads to a greater mechanical and chemical cleaning of oral tissues as compared to a standard toothbrush (6). Some twigs need to be moistened with water if they become too dry. The end can be cut for hygiene assurance. The twig toothbrush is replaced every few weeks for appropriate hygiene maintenance, and there is no need for toothpaste.

Twig toothbrushes can be prepared from various species of trees. Some trees are more appropriate for the protection and cleaning of the teeth, owing to their chemical composition. The miswak is prepared from the Salvadora persica tree, which is a native shrub to the Baluchestan area in southeast Iran and has religious origins. It is believed that this tool is the first toothbrush that Muslims used for brushing and cleaning their teeth as early as 1,400 years ago before religious practices. The derum comes from a walnut tree (Juglans regia). In African countries, twig toothbrushes are also prepared from Salvadora persica, which they call a toothbrush tree. An unusual south Africa female tribal custom includes brushing the teeth and gums with the chewed root of the Euclea natalensis tree; it is believed that this practice promotes oral health. This plant has antimicrobial properties and leaves a bright orange color in of the mouth of its users, similar to the $\operatorname{derum}(7)$.

Teeth-cleaning twigs have several advantages: they offer dental protection similar to toothbrushes; they are more ecological in their lifecycle; they can eliminate oral malodor; they have a lower cost and require little work to keep in good condition; and they often have volatile active antibacterial compounds. However, teeth-cleaning twigs have also several disadvantages: extensive scrubbing can damage the teeth and lead to gum recession $(8,9)$. The use of the miswak and derum is common in Baluchestanas seen in Figure 1.

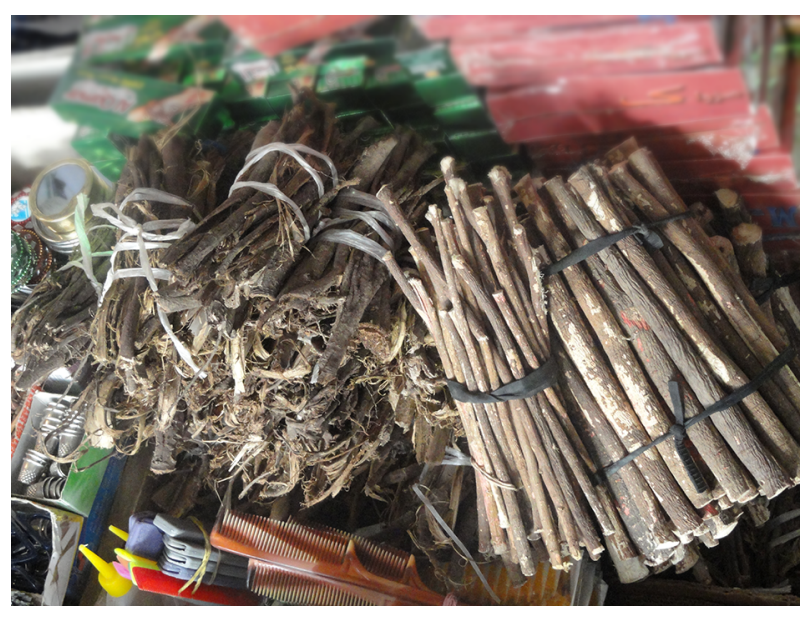

Figure 1. Miswak and Derum

The use of the miswak and derum was studied in the Baluchestan province using 1,000 dental patients, both immigrants and native people. From a sample of 159 people (15.9\% of the study population), 158 natives and 1 immigrant used either a miswak or a derum. The use of a derum was significantly more common in females than 
males $67 \%$ female versus $33 \%$ male $(\mathrm{P}<0.05)$. The females use it for cosmetic purposes; the transient discoloration of the mucosal and lips (orange color) by the derum is desirable. The use of a miswak was more common in males, especially in people above 40 years (95.6\% of the sample). The use of a miswak and/or derum is more common in villagers and residents of the southern area of the Baluchestan province (Chabahar and Iranshahr), especially in people with a low socioeconomic status (above $60 \%$ of the sample). According to the study, $90 \%$ of the users had developed enamel erosion and gingival recession. A precise assessment shows that natives use different kinds of herbal toothbrushes.

Studies and chemical analyses of herbal brushes show that they are commonly used in Southeast Iran. Through these studies, we can achieve important insights into the advantages and effective compounds of this type of brush. By adding toothpastes and mouth rinses, we can maximize its benefits.

\section{References}

1. Almas K. The effect of Salvadora persica extract (miswak) and chlorhex- idine gluconate on human dentin: a SEM study.J Contemp Dent Pract. 2002;3(3):27-35. [PubMed: 12239575].

2. Sofrata AH, Claesson RL, Lingstrom PK, Gustafsson AK. Strong antibacterial effect of miswak against oral microorganisms associated with periodontitis and caries. J Periodontol. 2008;79(8):1474-9. doi: 10.1902/jop.2008.070506. [PubMed: 18672998].

3. Al Sadhan RI, Almas K. Miswak (chewing stick): a cultural and scientific heritage. Saudi Dental J. 1999;11(2):80-7.

4. Halawany HS. A review on miswak (Salvadora persica) and its effect on various aspects of oral health. Saudi Dent J. 2012;24(2):63-9. doi: 10.1016/j.sdentj.2011.12.004. [PubMed: 23960531].

5. Darmani H, Nusayr T, Al-Hiyasat AS. Effects of extracts of miswak and derum on proliferation of Balb/C 3T3 fibroblasts and viability of cariogenic bacteria. Int J Dent Hyg. 2006;4(2):62-6. doi: 10.1111/j.16015037.2006.00149.x. [PubMed: 16637906].

6. Malik AS, Shaukat MS, Qureshi AA, Abdur R. Comparative effectiveness of chewing stick and toothbrush: a randomized clinical trial. $N$ Am J Med Sci. 2014;6(7):333-7. doi: 10.4103/1947-2714.136916. [PubMed: 25077082].

7. Martin S, Greenberg G, Lynch M. Textbook of Burket's Oral Medicine. 10th ed. BC Decker: Hamilton; 2008. p. 125.

8. Almas K, Skaug N, Ahmad I. An in vitro antimicrobial comparison of miswak extract with commercially available non-alcohol mouthrinses. Int J Dent Hyg. 2005;3(1):18-24. doi: 10.1111/j.1601-5037.2004.00111.x. [PubMed: 16451373].

9. Al-Otaibi M, Al-Harthy M, Soder B, Gustafsson A, Angmar-Mansson B. Comparative effect of chewing sticks and toothbrushing on plaque removal and gingival health. Oral Health Prev Dent. 2003;1(4):301-7. [PubMed: 15643758]. 